\title{
RELAÇÃO DA FREQUÊNCIA DE PROXIMIDADE E COMPORTAMENTO DE NOVILHAS LEITEIRAS CRIADAS A PASTO
}

\author{
(Relationship of the frequency of proximity and behaviors of dairy heifers raised on pasture) \\ ${ }^{1,2}$ Karolini Tenffen de Sousa, ${ }^{2}$ Matheus Deniz, ${ }^{2}$ Laura Arias Avilés, ${ }^{2}$ Camila de Almeida Franceschi, ${ }^{2}$ Aline \\ Aparecida Cerino, ${ }^{2}$ Luiz Carlos Pinheiro Machado Filho \\ ${ }^{1}$ Universidade Federal do Paraná, Curitiba, Paraná, Brasil. ²Universidade Federal de Santa Catarina, Brasil.
}

\section{*Correspondência: karoltenffen10@hotmail.com}

RESUMO: A distribuição espacial dos bovinos na pastagem não ocorre de forma aleatória, sendo que a proximidade com outros animais pode refletir laços sociais formados dentro do rebanho (GYGAX et al., 2010; VAL-LAILLET et al., 2009). Alguns animais permanecem mais próximos de indivíduos específicos em relação ao restante do rebanho, demostrando certa preferência. A frequência de proximidade entre bovinos é dita como interação positiva, pois está presente em organizações sociais complexas e auxilia na manutenção da relação estável entre os animais envolvidos. O objetivo deste estudo observacional foi descrever a frequência de proximidade entre novilhas leiteiras durante seus comportamentos diurnos. $O$ experimento foi realizado entre os meses de outubro e dezembro de 2017, no Biotério de Bovinos da Fazenda Didático-Experimental da Ressacada (FER), pertencente a Universidade Federal de Santa Catarina, Florianópolis, Brasil. Foram observadas 19 novilhas mochas (secas e não-prenhas) mestiças (Jersey x Holandês), com aproximadamente 48 meses de idade e peso médio de $355 \pm 40 \mathrm{~kg}$. Na FER os animais são manejados sob Pastoreio Racional Voisin, adentrando um novo piquete $\left(2.500 \mathrm{~m}^{2}\right)$ a cada $24 \mathrm{~h}$. As observações ocorreram durante 20 dias, alternando entre os períodos matutino (8:00-12:00) e vespertino (14:00-18:00). Os comportamentos pastando, ócio em pé, ócio deitado, ruminando em pé, ruminando deitado, outros (ingestão de água, defecando, urinando, allogrooming e self grooming) e a proximidade foram avaliados através de instantâneos a cada 10min. Duas novilhas foram consideradas próximas quando estavam a uma distância, de aproximadamente dois metros, da paleta da novilha focal. Independente do período (matutino e vespertino), o comportamento pastando apresentou a maior frequência $(62,42 \%)$ em relação aos demais. A maior frequência dos comportamentos avaliados foi observada quando a novilha estava sozinha $(69,2 \%)$, próxima a uma (24,4\%) e duas novilhas (6,4\%). Quando próxima a outra novilha (uma ou duas), a novilha focal foi observada com maior frequência pastando $(47,8 \%)$, seguido de ócio $(28,2 \%)$, ruminando $(19,4 \%)$ e realizando outros comportamentos $(4,6 \%)$. Durante o período matutino, as novilhas realizaram preferencialmente os comportamentos de ócio (em pé: $16,6 \%$; deitado: 14,5\%) e ruminação (em pé: $4,9 \%$; deitado: $13,3 \%$ ). O comportamento de ócio em pé foi observado com maior frequência quando próxima de outra novilha (em pé: 19,3\%, deitada: 8,8\%). Para o comportamento de ruminação ocorreu o inverso, as novilhas ruminaram com maior frequência próxima de outra quando estavam deitadas (em pé: $5,7 \%$, deitada: 13,7\%). Fatores como as associações preferenciais, disponibilidade de alimento e a hierarquia social, podem explicar a distribuição espacial dos animais (GYGAX et al., 2010). Assim, a compreensão da organização dos bovinos permite adaptações nas instalações e práticas de manejo para melhorar o bem-estar dos animais de produção. Concluímos, que o principal comportamento realizado em companhia de outra novilha foi o pastoreio.

Palavras-chave: bem-estar; comportamento social; etologia aplicada; interações positivas.

\section{Agradecimentos}

Coordenação de Aperfeiçoamento de Pessoal de Nível Superior (CAPES) pela bolsa concedida à primeira autora.

\section{Nota}

Este trabalho foi aprovado pela Comissão de Ética no Uso de Animais da Universidade Federal de Santa Catarina sob protocolo número 1004100516. 


\section{Referências}

GYGAX, L.; NEISEN, G.; WECHSLER, B. Socio-spatial relationships in dairy cows. Ethology, v. 116, n. 1, p. $10-23,2010$.

VAL-LAILLET, D. et al. Allogrooming in cattle: Relationships between social preferences, feeding displacements and social dominance. Applied Animal Behaviour Science, v. 116, n. 2-4, p. 141149, 2009. 